\title{
3-dimensional numerical modelling of rolling of superconducting Ag/BSCCO tape
}

\author{
Eriksen, Morten; Bech, Jakob Ilsted; Seifi, Behrouz; Bay, Niels
}

Published in:

I E E E Transactions on Applied Superconductivity

Link to article, DOI:

10.1109/77.919881

Publication date:

2000

Document Version

Publisher's PDF, also known as Version of record

Link back to DTU Orbit

Citation (APA):

Eriksen, M., Bech, J. I., Seifi, B., \& Bay, N. (2000). 3-dimensional numerical modelling of rolling of superconducting Ag/BSCCO tape. I E E E Transactions on Applied Superconductivity, 11(1), $3756-3759$. https://doi.org/10.1109/77.919881

\section{General rights}

Copyright and moral rights for the publications made accessible in the public portal are retained by the authors and/or other copyright owners and it is a condition of accessing publications that users recognise and abide by the legal requirements associated with these rights.

- Users may download and print one copy of any publication from the public portal for the purpose of private study or research.

- You may not further distribute the material or use it for any profit-making activity or commercial gain

- You may freely distribute the URL identifying the publication in the public portal 


\title{
3-DIMENSIONAL NUMERICAL MODELLING OF ROLLING OF SUPERCONDUCTING Ag/BSCCO TAPE
}

\author{
M. Eriksen' ${ }^{1}$ J. I. Bech ${ }^{2}$, B. Seifi' ${ }^{2}$ and N. Bay ${ }^{2}$, \\ ${ }^{1}$ Institute for Product Development (IPU), Technical University of Denmark (DTU), bldg. 425, DK- \\ 2800 Lyngby, Denmark \\ ${ }^{2}$ Department of Manufacturing Engineering (IPT), Technical University of Denmark (DTU), bldg. \\ 425, DK-2800 Lyngby, Denmark
}

\begin{abstract}
Numerical simulation of the deformation process during flat rolling of multifilament HTS tapes has been investigated using a commercial FEM program, ELFEN. The numerical models were built up in 2D and 3D using a DruckerPrager/Cap model for the powder. Three different roll diameters $(\varnothing 24 \mathrm{~mm}, \varnothing 85 \mathrm{~mm}$ and $\varnothing 126 \mathrm{~mm}$ ) have been investigated.

It is found that it is possible to perform numerical simulation with 3D models of flat rolling of multifilament wire. Two 3D models have been used; 3D pressing with rolls and 3D rolling. 3D pressing with rolls have the advance that the simulation time is lower than in the 3D rolling. The 3D models have the advantage compared to $2 \mathrm{D}$ pressing that they can predict the 3 dimensional flow in the flat rolling, which has been showed to be very imported for the super conduction properties.
\end{abstract}

Index Terms-Finite Element Modelling, superconductor, flat rolling.

\section{INTRODUCTION}

$\mathrm{M}$ anufacturing of superconducting tapes by the oxide powder in tube (PIT) technique implies several different mechanical processes.

The ceramic powder in terms of pressed bars is initially inserted into a silver tube. Wire drawing is used to reduce the composite tube to long, thin single- and multifilament wires. The multifilament wire is reduced to tape by flat rolling. The tape is finally heat-treated in order to sinter the powder and to form a superconducting, ceramic phase.

The flat rolling process implies large inhomogeneous strains and increased density. The rolling parameters and the resulting stresses and strains are crucial for the quality of the final tape. Quality parameters to be optimised are filament geometry, density, texture, and defects like cracks and localised shear.

Homogeneity of the tape cross-section can be improved by rolling from square wire alternatively to round as shown by Eriksen et al. $/ 3 /$. Bech et al. $/ 17 /$ and Eriksen et al. conclude that length and width strain should be equal in the rolling process.
Numerical modelling of mechanical processing of $\mathrm{Ag} / \mathrm{BSCCO}$ composite tapes by the finite element method (FEM) is a complicated task still not widely applied.

In the references [2], [11] and [13] drawing of singlefilament wire is modelled by 2-dimensional axissymmetric models. These authors all apply the commercial FEM code ABAQUS. The constitutive model describing the powder flow is the Drucker-Prager/Cap model with an elliptical cap. Process parameters such as the die angle and degree of reduction in each drawing step are shown to influence the density of the powder in the drawn wire. The distribution of density being high at the silver/powder interface and lower in the centre is in agreement with experiments. FEM modelling of drawing of multifilament wire has not been found in literature, probably because a full 3-dimensionsal model is required.

Numerical modelling of flat rolling also requires a 3D model to describe the strains in the length, width and thickness directions. Simplified 2D models can, however, be made assuming zero strain in either the width or the length direction.

Assuming zero width strain the pressure distribution along the roll gap can be modelled [9], [10] and [12]. The pressure profile forms either a friction hill or a friction valley depending on the roll diameter and degree of reduction. These parameters also influence the shear strains in the deformation zone.

When material flow in the cross-section is analysed in a $2 \mathrm{D}$ model, zero strain in the length direction must be assumed, [3] and [16]. This technique enables prediction of filament geometry and density incorporating the influence of wire geometry and friction.

Full 3-dimensional simulations of flat rolling of wire have been carried out for stainless steel wire, [14] and [15]. Comparison between numerical and experimental results shows good agreement. It is concluded that strain induced anisotropy is of major importance to the ratio between length strain and width strain.

The input data for material properties are essential for the precision of numerical results. Testing the mechanical 
properties of a ceramic powder is a complicated task. Reference [5] presents an extensive investigation of the mechanical properties of BSCCO powder. The powder is evaluated applying a combination of fracture tests and triaxial deformation tests. It is concluded that a Drucker-Prager/cap model is not capable of describing the yield surface of BSCCO powder in detail, and a new constitutive model is proposed. Reference [1] describes how the yield surface can be determined by a few relatively simple tests combined with a Drucker-Prager/conical cap model. It is demonstrated that a FEM simulation based on this approach gives a rather good prediction of the density in the individual filaments for small reductions in a $2 \mathrm{D}$ model. A $50 \%$ deviation in deviatoric yield stress between [1] and [5] may be caused be strain induced anisotropy in [1].

This paper presents $2 \mathrm{D}$ and $3 \mathrm{D}$ numerical modelling of flat rolling. Numerical results are compared to experimental results applying rolls of diameter $\emptyset 24 \mathrm{~mm}, \emptyset 85 \mathrm{~mm}$ and $\emptyset 126$.

\section{FEM MODELS}

The modelling is done by the commercial FEM program Elfen by Rockfield Software Itd. Elfen has optional implicit or explicit codes. Implicit and explicit codes have been compared in the references [4] and [12]. They conclude that the explicit code gives satisfactory results compared to experiments and results obtained with the implicit code. The explicit codes have no problem with converging and requires much less computer power and time, especially for $3 \mathrm{D}$ simulations. In the present work the explicit code was chosen.

Three different approaches have been applied for modelling of flat rolling, that is $2 \mathrm{D}$ pressing, 3D pressing between non-rotating rolls and full $3 \mathrm{D}$ rolling. The preformed wire cross section shown in figure $2 b$ is the same for all simulations. The number of elements in the mesh are $50 \times 50$ for $2 \mathrm{D}$ pressing, $17 \times 26 \times 60$ (number of element in width $\mathrm{x}$ height $x$ length) for $3 D$ pressing and $9 \times 12 \times 60$ or $17 \times 26 \times 60$ for $3 \mathrm{D}$ rolling. The rectangular filaments lie in a matrix of pure silver surrounded by an alloyed silver sheath. Both silver materials are described by Von Mises yield criterion and the flow stress parameters are given in table 1.

$\sigma=C \varepsilon^{n}$

The constitutive plasticity model describing the powder is the Drucker-Prager/cap model with a conical cap. This model is a rough approximation to the real yield surface, but it includes the most important properties of the powder, which are pressure dependent yield stress, volumetric strain and hardening. In the $\left(\mathrm{p},\left(\mathrm{J}_{2}\right)^{1 / 2}\right)$ plane the yield surface consists of two intersecting lines as seen in figure 1 . The Drucker-Prager failure surface is written as

$$
F_{s}=\sqrt{J_{2}}-\eta\left(p+p_{l}\right)=0
$$

where $\eta$ is the slope of the failure line and $p_{t}$ is the yield stress in pure, hydrostatic tension. The cap yield surface is a line with a negative slope

$$
F_{c}=\sqrt{\int_{2}}+\xi\left(p-p_{c}\right)=0
$$

where $-\xi$ is the slope of the cap line and $p_{c}$ is the hydrostatic compression yield stress. The model parameters, extracted from reference [5], are listed in table 1.

$\begin{array}{lccc} & \text { Pure silver } & \text { Alloy silver } & \text { Powder } \\ \text { Yungs modulus } & 57.320 \mathrm{MPa} & 57.320 \mathrm{MPa} & 13.790 \mathrm{MPa} \\ \text { Poisons ratio, } v & 0.38 & 0.38 & 0.2 \\ \sigma=\mathrm{C} \varepsilon^{\mathrm{n}} & & & \\ \mathrm{C} & 320 \mathrm{MPa} & 350 \mathrm{MPa} & \\ \mathrm{n} & 0.3 & 0.11 & \\ \eta \text { Friction Slope } & & & 1.2 \\ \eta \text { Dilatance Slope } & & 1.2 \\ \xi \text { Cap Slope } & & 0.29 \\ \mathrm{P}_{\mathrm{t}} \text { Tensile Stress } & & 12 \mathrm{MPa} \\ \mathrm{P}_{\mathrm{c}}=\mathrm{a}^{*}\left(\exp \left(\mathrm{b}\left(\rho-\rho_{0}\right)-1\right)\right. & & \\ \quad \mathrm{a} & & 27 \\ \quad \mathrm{~b} & & 1 \\ \quad \text { Relative density } \rho_{0} & & 0,6 \\ \end{array}$

Table 1. Material data for pure silver, alloy silver and BSCCO powder, after [5].

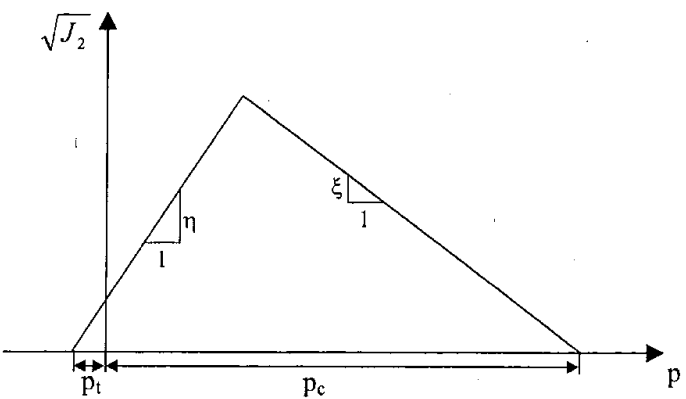

Fig. 1 - Drucker-Prager/Cap model

\section{EXPERIMENTAL RESULTS}

For the experimental investigation rectangular filaments were packed in three columns and nine rows in a square outer tube with outer dimension $10 \mathrm{~mm} \times 10 \mathrm{~mm}$. The multifilament wire was drawn in 38 steps with nine intermediate annealings to $1.02 \mathrm{~mm} \times 1.02 \mathrm{~mm}$. The area reduction was gradually increased from $2 \%$ to $20 \%$ pr step during the drawing sequence. Figure $2 \mathrm{a}$ shows the wire crosssection. The wire was cut in three pieces and flat rolled with respectively $\varnothing 24 \mathrm{~mm}, \varnothing 85 \mathrm{~mm}$ and $\varnothing 126 \mathrm{~mm}$ rolls in one step, see figure 3.

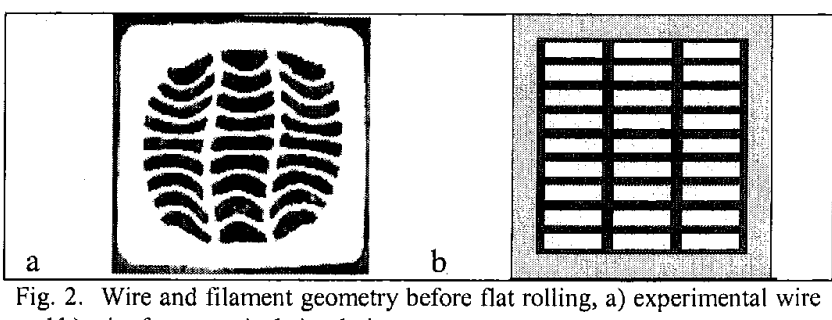
and $b$ ) wire for numerical simulation.

The relative powder density was evaluated by combining weight and cross-sectional area measurements of wire and tapes. The mean relative density of powder in the wire before rolling is 0.60 . The densities in the green tapes after rolling are $0.77,0.81$ and 0.87 for tapes rolled with $ø 24 \mathrm{~mm}, \emptyset 85$ 
$\mathrm{mm}$ and $\varnothing 126 \mathrm{~mm}$ respectively. The width of the tapes and consequently the individual filaments increase with increasing roll diameter as seen in figure 3.

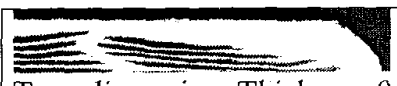

Tape dimension: Thickness $0.25 \mathrm{~mm}$, width $1.6 \mathrm{~mm}$

\section{$\Longrightarrow$}

Tape dimension: Thickness $0.2 \mathrm{~mm}$, width $2.2 \mathrm{~mm}$

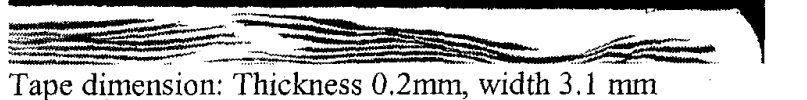

Tape dimension: Thickness $0.2 \mathrm{~mm}$, width $3.1 \mathrm{~mm}$

Fig. 3. Filament geometry after flat rolling with three different roll diameters, a) Ø24 mm, b) Ø85 mm and c) Ø126 mm.

\section{Numerical results}

Figure 2 shows the cross-sections of the wire and the model. The simplified geometry of the filaments in the model allows a structural mesh, which reduces calculation time. On the image of the model it is possible to distinguish the pure silver (dark grey) from the alloyed silver (grey) and the powder (white). The initial powder density is 0.6 in all simulations.

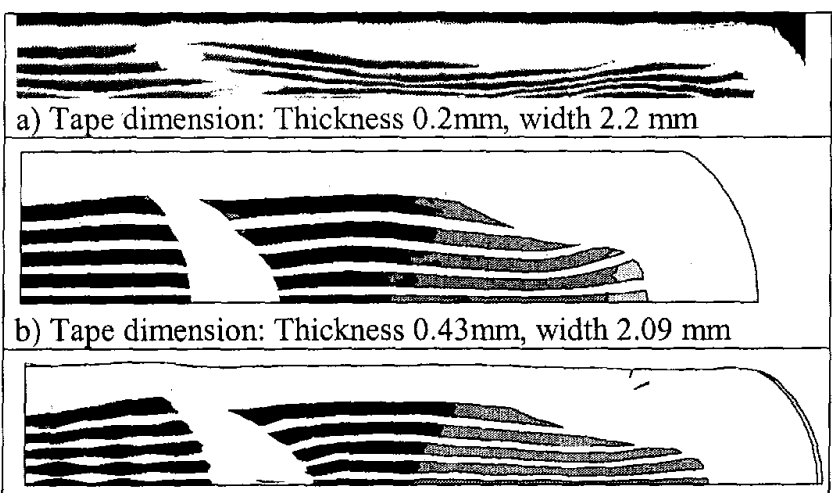

c) Tape dimension: Thickness $0.32 \mathrm{~mm}$, width $2.26 \mathrm{~mm}$

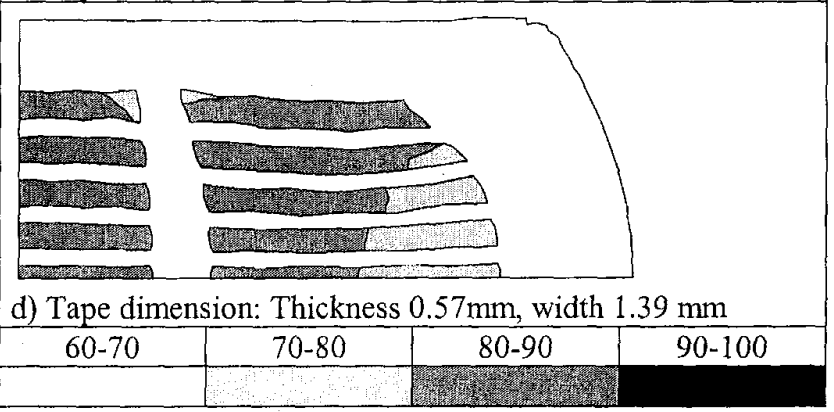

Fig. 4. a) Geometry of experimentally flat rolled tape with $085 \mathrm{~mm}$ rolls, b) relative density in 2D FEM simulation of pressing, c) relative density in 3D simulation of pressing with $085 \mathrm{~mm}$ rolls and d) relative density in $3 \mathrm{D}$ simulation of rolling with $\varnothing 85 \mathrm{~mm}$ rolls.

Figure 4 compares a tape rolled with $\varnothing 85 \mathrm{~mm}$ rolls to the numerical results of $2 \mathrm{D}$ pressing, 3D pressing and $3 \mathrm{D}$ rolling.

The tapes do not have the same final thickness. For 2D and 3D pressing further reduction was hindered by numerical problems. For 3D rolling the relatively coarse mesh $(9 \times 12 \times 60$ elements) was distorted at high reductions.

The densities of the filaments are displayed by different shades of grey referring to the colour code. The calculated relative densities are in the range from $80 \%$ to more than $90 \%$. All three models calculate higher densities in the centre than at the edges. The tape experimentally rolled with $\emptyset 85$ $\mathrm{mm}$ rolls has filament densities varying from $78 \%$ at the edge to $85 \%$ in the centre giving a mean value about $81 \%$. This shows that all three models overestimate the relative density.

In figure 5 the relation between tape thickness and tape width is shown for 2D and 3D FEM simulations of rolling and pressing. Experimental results with $\emptyset 85 \mathrm{~mm}$ rolls are plotted too for comparison. It is seen that the $3 \mathrm{D}$ rolling simulation fits very well with the experimental results and that FEM simulations of $3 \mathrm{D}$ pressing and $2 \mathrm{D}$ pressing overestimate the widening.

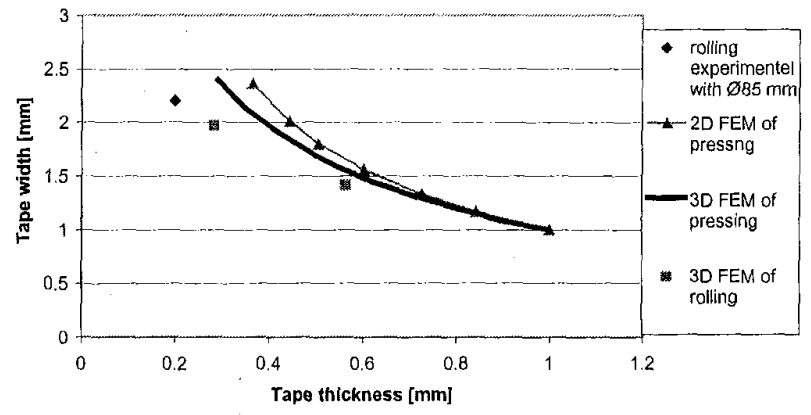

Fig. 5. Tape width vs. tape thickness for experiments with $\emptyset 85 \mathrm{~mm}$ rolls and $2 \mathrm{D}$ and $3 \mathrm{D}$ FEM simulations.

Figure 6 shows the cross sections after numerical 3D pressing of the multifilaments with three different roll diameters. The width of the tapes increase with increasing roll diameter as observed experimentally, but both the tape widths and the relative densities are overestimated.

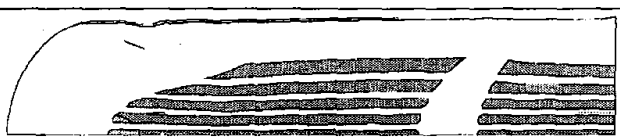

a) Tape dimension: Thickness $0.31 \mathrm{~mm}$, width $1.73 \mathrm{~mm}$

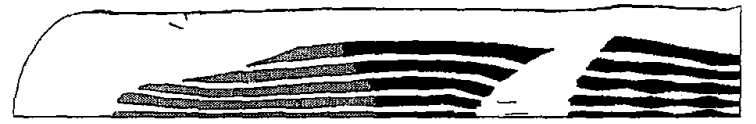

b) Tape dimension: Thickness $0.32 \mathrm{~mm}$, width $2.26 \mathrm{~mm}$

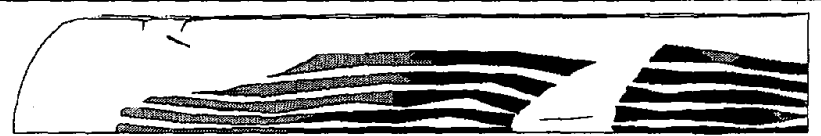

c) Tape dimension: Thickness $0.33 \mathrm{~mm}$, width $2.38 \mathrm{~mm}$ \begin{tabular}{|l|c|c|c|}
\hline $60-70$ & $70-80$ & $80-90$ & $90-100$ \\
\hline
\end{tabular}

Fig. 6. Numerical estimated filament density after $3 \mathrm{D}$ pressing with three different roll diameters, a) $\varnothing 24 \mathrm{~mm}$, b) $\varnothing 85 \mathrm{~mm}$ and c) $\varnothing 126 \mathrm{~mm}$

FEM simulation of rolling with two different meshes has been performed. Rolling with $9 \times 12 \times 60$ elements cause problems with distorted elements if the deformation is too large. The problem is eliminated by increasing the number of elements from $9 \times 12 \times 60$ to $17 \times 26 \times 60$. The number of elements only has a small effect on the tape dimensions and powder density.

Figure 7 shows the results after 3D rolling with $\varnothing 24 \mathrm{~mm}$ rolls and $\varnothing 85 \mathrm{~mm}$ rolls. It is seen that problems with distorted 
elements are just initialised for rolling with the $\varnothing 24 \mathrm{~mm}$ rolls, where only $9 \times 12 \times 60$ elements are used. Tape rolled with $\emptyset 85$ $\mathrm{mm}$ rolls with, a mesh density of $17 \times 26 \times 60$ elements, shows no problems with distorted elements. 3D numerical modelling of rolling of multifilament wire gives the possibility of optimising the rolling process regarding stresses, strains and density in the deformation zone.

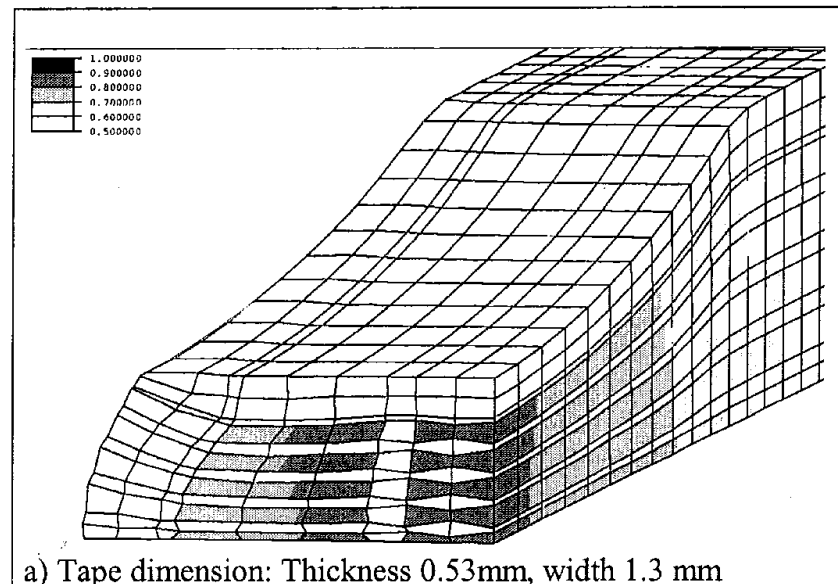

a) Tape dimension: Thickness $0.53 \mathrm{~mm}$, width $1.3 \mathrm{~mm}$

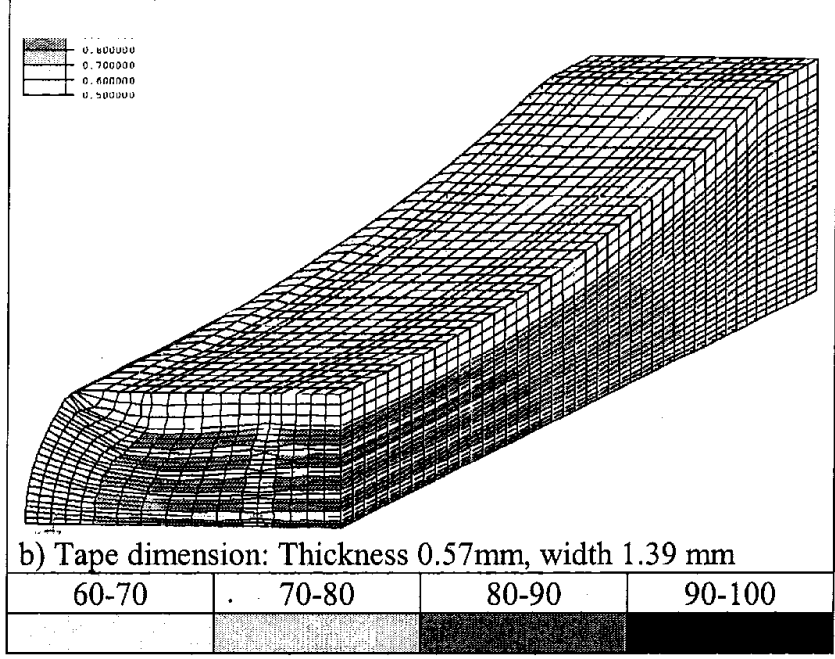

Fig. 7. Numerical estimated filament density after flat rolling with three different roll diameter, a) $\emptyset 24 \mathrm{~mm}$ and b) $\varnothing 85 \mathrm{~mm}$.

\section{CONCLUSIONS}

The three different approaches for modelling rolling of $\mathrm{Ag} / \mathrm{BSCCO}$ tape each have their drawbacks and advantages. One of the limiting factors is calculation time. A coarser mesh can reduce time. But the coarse mesh can give numerical problems and lack of details in the numerical results. The 2D model allows very detailed prediction of the geometry in the cross-section in the case of plane strain. 3D flat rolling will of course be the most accurate model for flat rolling because it is closest to the real process. But the current simulation of 3D rolling with $17 \times 26 \times 60$ elements takes 6 weeks to perform using an $800 \mathrm{MHz}$ PC. 3D pressing with $17 \times 26 \times 60$ elements take 3 weeks and 2D pressing takes 4 hours to perform.

The too high densities predicted by the numerical simulations are probably caused by the relatively simple constitutive powder model applying very rough geometries for the yield surface and plastic potential.

In order to obtain better results improved powder models and friction data are required. Faster computers and faster codes can reduce the simulation time or make it possible to increase the mesh density and the accuracy of the results.

\section{REFERENCES}

[1] Bech,J., Eriksen,M., Toussaint,F., Doremus,P. and Bay,N.:"Mechanical characterisation of superconducting, BSCCO powder.". Submitted for Powder Metallurgy World Congress \& Exhibition 2000

[2] Tangrila, S., Shah,R. and Rachakonda, S.:"Densification behavior of BSCC-2212 superconduction powder during the wire drawing of powder-in-tube (PIT) samples". AMD-Vol.216, Net Shape Processing of Powder Materials. ASME 1995.

[3] Eriksen, M., Bech,J.I., Bay, N., Skov-Hansen,P. and Wang, W.G.."Flat rolling of round and square superconducting multifilaments for HTS tapes". EUCAS'99. Paper no.12-75.

[4] Danckert, J.:"Explicit versus implicit FEM in the analysis of metal forming processes". NSXM VIII Eighth Nordic Seminar on Computational Mechanics, 1995. ISSN 0347-9226.

[5] Gurson, A.L and Yuan, D.W.:"A material model for a ceramic powder based on ultrasond, TRS bend bar, and axisymmetric triaxial conpression test results". AMD-Vol.216, Net Shape Processing of Powder Materials, ASME 1995.

[6] Zipse, H.: "Finite-Element Simulation of the Die Pressing and Sintering of a Ceramic Component". Journal of the European Ceramic Society 17 (1997) 1707-1713.

[7] Parrell, J.A., Polyanskii, A.A, Pashitski, A.E. and Larbalestier, D.C.: "Direct evidence for residual, preferentially-oriented cracks in rolled and pressed Ag-clad BSCCO-2223 tapes and their effect on the critical current density". Supercond. Sci. Technol. 9 (1996) 393-398.

[8] Skov-Hansen, P. and Han,Z:: "Stresses and Strains in Multi-Filament HTS Tapes". IEEE Transactions on applied superconductivity, Vol. 9, No. 2, June 1999.

[9] Dvorkin, E.N., Goldschmit, M.B. Cavaliere, M.A., Amanta, P.M. Marini, $\mathrm{O}$ and Stroppiana, W. "2D finite element parametric studies of the flat-rolling process". Journal of Materials Processing Technology 68 (1997) 99-107.

[10] Schoenfeld, S.E., Asaro, R.J. and Ahzi, S.: "The bulk processing of 2223 BSCCO powders, II. Tape rolling". Philosophical Magazine A, 1996, Vol.73, No. 6, 1591-1620

[11] Shah, R., Tangrila, S. Rachakonda, S. and Thirukkonda, M.: "Finite Element Modeling of the Powder-in-Tube Process for Manufacture of BSCCO-2212 Superconducting Wires". Journal of Electronic Materials, Vol. 24. No. 12, 1995.

[12] Lindgren, L.E. and Edberg, J.: "Explicit versus implicit finite element formulation in simulation of rolling". Journal of Materials Processing Technology, 24 (1990) 85-94

[13] Malberg, M., Bech, J. and Bay, N.: "Influence of process parameters in drawing of superconducting wire". IEEE transactions on applied superconductivity, volume 9, no. 2, page 2577-80, 1999.

[14] Carlsson, B. and Lagergren, J.: "The deformation of drawn wire in flat rolling". PD-Vol.75, Engineering Systems Design and Analysis. Volume 3, ASME 1996.

[15] Carlsson, B.: "The contact pressure distribution in the flat rolling of wire". Journal of Materials Processing Technology 73(1998) I-6

[16] Kaagaard, T.R. and Myhlendorph, B.: "Finite element simulation of superconduction compositet material". (M. Sc. thesis in danish) Aalborg Universitet, Denmark, 1998

[17] Bech. J., Seifi, B., Eriksen, M., Bay, N., Skov-Hansen, P. and Wang, W.G.: "Influence of strains in flat rolling on $J_{c}$ of superconducting AG/BSCCO-2223 tapes with thin, homogenous filaments". EUCAS'99, paper no.16-17. 1999. 